\title{
Synthesis, characterization, and application of easily accessible resin-encapsulated nickel nanocatalyst for efficient reduction of functionalized nitroarenes under mild conditions
}

\author{
POONAM RANI, KAMAL NAIN SINGH and AMARJIT KAUR*(D) \\ Department of Chemistry, Faculty of Science, Panjab University, Chandigarh 160014, India \\ E-mail: amarjitk@pu.ac.in
}

MS received 5 May 2018; revised 16 August 2018; accepted 25 August 2018; published online 10 November 2018

\begin{abstract}
A novel resin-encapsulated nickel nanocatalyst has been synthesized by a modified impregnation method using nickel acetate tetrahydrate in presence of sodium borohydride as a mild reducing agent. The synthesized nanocatalyst was characterized by field emission scanning electron microscopy (FESEM) and transmission electron microscopy (TEM). The concentration of nickel nanoparticles encapsulated on resin was determined by inductively coupled plasma-mass spectroscopy (ICP-MS). Further, synthesized resinencapsulated nickel nanocatalyst was found to be stable and efficient in micromolar concentrations, for the selective reduction of functionalized nitroarenes to corresponding amines in good to high yield, under mild reaction conditions. The nanocatalyst shows excellent reusability.
\end{abstract}

Keywords. Resin-encapsulated nickel nanocatalyst; impregnation; stability; recyclability; reduction; nitroarenes; aromatic amines.

\section{Introduction}

Nitroarenes are generally employed in a wide range of industries for the synthesis of many valuable materials such as dyes, pesticides, explosives, polymers, pharmaceuticals, etc. Excessive discharge of these nitro compounds from industries into the wastewater has led to environmental pollution. ${ }^{1}$ Their mutagenic and carcinogenic nature affect extensively the entire range of living organisms including humans as they are heavily dependent on water and aquatic products in everyday life. Moreover, these nitro compounds have been declared as the second largest group of organic environmental pollutants. ${ }^{2}$ Therefore, it is necessary to eliminate these nitro compounds from the waste water and land. Principles of green chemistry endorse the replacement of hazardous chemicals by using environment-friendly alternatives. Among the various reported methods, ${ }^{3-6}$ the transformation of nitroarenes to their corresponding amines is the most significant and sustaining strategy that contributes to the environmental fate of nitroarenes. The aromatic amines so obtained are generally employed as the important building blocks in the synthesis of drugs, biologically active compounds, dyes, agrochemicals, pharmaceuticals, polymers, corrosion inhibitors, surfactant, herbicides, etc. ${ }^{7-9}$ Conventional methods for the reduction of nitroarenes include certain drawbacks such as long reaction time, use of toxic and carcinogenic solvents, expensive noble metal complexes, generation of a large amount of waste and non-reusability of the catalysts, etc. ${ }^{10-12}$

The importance of amines in the above-mentioned industries and efforts in surface science have led to the discovery of new heterogeneous catalysts either by impregnation of unsupported metal nanoparticles or highly dispersed metal precursors to different supports for the reduction of nitroarenes using various reducing agents such as $\mathrm{H}_{2}, \mathrm{NaBH}_{4}, \mathrm{~N}_{2} \mathrm{H}_{4} \cdot \mathrm{H}_{2} \mathrm{O}$ and so on. ${ }^{13-15}$ Many support materials such as polymers, dendrimers, carbonaceous porous materials, metal oxide, etc., are in trend to arrest the agglomeration and the high surface energy of metal nanoparticles. ${ }^{16-20}$

\footnotetext{
*For correspondence

Electronic supplementary material: The online version of this article (https://doi.org/10.1007/s12039-018-1548-7) contains supplementary material, which is available to authorized users.
} 
Usually, heterogeneous catalysts including noble metals (palladium, platinum, gold, and silver) are the most widely sourced supported catalysts for the reduction of nitroarenes. ${ }^{21-25}$ The high price of these precious noble metals limit their large-scale applications. Current research activities in this area are mainly focused on the development of the heterogeneous catalysts based on base-metals (nickel, iron, copper, and cobalt) for efficient and cost-effective catalytic selective reduction of nitroarenes. ${ }^{26-29}$

Many supported nickel nanocatalysts and their versatile applications in the field of medical diagnosis, ${ }^{30}$ supercapacitors, ${ }^{31}$ and catalysis ${ }^{32-35}$ especially for the reduction of nitroarenes are reported in the literature. Kalbasi and co-workers developed nickel nanoparticles@polyvinylamine/SBA-15 composite (PVAm/SBA-15), to be used in most of the solvents as an efficient heterogeneous catalyst for hydrogenation of aromatic nitro compounds to corresponding aromatic amino compounds in good yields by employing sodium borohydride as a reducing agent. ${ }^{36}$ Figueiredo et al. generated nickel nanoparticles by metal disintegration. These were stabilized on the top of the filamentous carbon. This nanocomposite was tested as a catalyst for the reduction of nitrobenzene under 1.5 MPa hydrogen pressure at $120^{\circ} \mathrm{C}$ with excellent performance producing clean aniline (approx. $99 \%$ yield). ${ }^{37}$ Ranu and co-workers reported the excellent use of $\mathrm{Fe}(0)$ nanoparticles stabilized by citric acid, for reduction of nitroarenes. The reaction was done using 3 equiv. nanoparticles per 1 equiv. of substrate in water for $3-4 \mathrm{~h}$ to obtain desired products in good yield. ${ }^{38}$ The commercially available amberlite XAD-4 resin used as a solid support for nanoparticles has advantages like easy to handle, non-reactive, easily available, porous nature, thermal and chemical stability. ${ }^{39}$ This has not been so far explored for the synthesis of nickel nanoparticles.

We have synthesized the amberlite XAD-4 resinencapsulated nickel nanocatalyst by the chemical reduction of nickel acetate tetrahydrate $\left(\mathrm{Ni}(\mathrm{OAc})_{2} \cdot 4 \mathrm{H}_{2} \mathrm{O}\right)$ in ethanol. Further, we have investigated the reduction of functionalized nitroarenes by the resin-encapsulated nickel nanocatalyst as a heterogeneous catalyst, using sodium borohydride as a reducing agent under mild reaction conditions. Thus, catalytic reduction of nitroarenes by resin-encapsulated nickel nanocatalyst may be of direct use in the treatment of waters contaminated with nitroarenes if the resulting amines can be removed by subsequent treatment. The resinencapsulated nickel nanocatalyst was recycled five times without any significant loss of its catalytic activity.

\section{Experimental}

\subsection{Materials and methods}

Unless otherwise stated, all reactions were carried out without taking precautions to exclude air and moisture. Nickel acetate tetrahydrate $\left(\mathrm{Ni}(\mathrm{OAc})_{2} \cdot 4 \mathrm{H}_{2} \mathrm{O}, 98 \%\right)$ was procured from Qualikems, India, sodium borohydride $\left(\mathrm{NaBH}_{4},>96 \%\right)$ from Spectrochem, India, absolute ethanol (99.9\%) from Changshu chemicals, China, and amberlite XAD-4 resin (of high purity) from Sigma-Aldrich, Germany, and used as received. Hydrochloride acid (37\%) and other solvents were of analytical grade and supplied by qualigens chemicals, India and were used after purification by standard procedures. All reaction temperatures refer to oil bath temperatures. Silica gel (230-400 mesh) (of high purity grade) for column chromatography, was purchased from Fisher Scientific Ltd, India. ${ }^{1} \mathrm{H}$ NMR and ${ }^{13} \mathrm{C}$ NMR spectra were recorded on model Avance-II (Bruker) 400 spectrometer operating at $400 \mathrm{MHz}$ $\left({ }^{1} \mathrm{H}\right)$ and $100 \mathrm{MHz}\left({ }^{13} \mathrm{C}\right)$. FESEM images were recorded using HITACHI SU8010 field emission scanning electron microscope. HR-TEM images and TEM-EDS analysis were obtained using a Tecnai ${ }^{\mathrm{TM}} \mathrm{G} 220,120 \mathrm{kV}$ transmission electron microscope with embedded CCD Camera. ICP-MS study was done on Agilent's 7700x, ICP-MS system. UV-Vis study for reduction of functionalized nitroarenes was carried out using UV-Visible spectrophotometer JASCO model V-530 using a $1 \mathrm{~cm}$ path length quartz cell.

\subsection{Synthesis of resin-encapsulated nickel nanocatalyst}

In a typical synthetic protocol, $5 \mathrm{~g}$ of resin beads were added to $25 \mathrm{~mL}$ of $5.0 \mathrm{mmol}$ nickel acetate tetrahydrate solution prepared in ethanol and stirred at room temperature for 3-4h followed by dropwise addition of $0.1 \mathrm{M}$ aq. $\mathrm{NaBH}_{4}-$ solution $(10 \mathrm{~mL})$. The addition of $\mathrm{NaBH}_{4}$ solution turns resin beads black, indicating the formation of nickel nanoparticles. The synthesized nanoparticles were first washed with distilled water followed by ethanol to control surface oxidation. This synthesized resin-encapsulated nickel nanocatalyst was then stored in absolute ethanol and is referred to as resin stabilized nickel nanocatalyst (Ni@XAD-4 nanocatalyst).

\subsection{General procedure for catalytic reduction}

To an oven dried $50 \mathrm{~mL}$ round bottom flask, charged with nitroarene $(1.5 \mathrm{mmol})$ and $10 \mathrm{~mL}$ of methanol: water $(3: 7)$ was added resin-encapsulated nickel nanocatalyst $(300 \mathrm{mg}$ of resin) $(0.161 \mathrm{mg}$ of $\mathrm{Ni} \approx 0.00275 \mathrm{mmol}$ of $\mathrm{Ni})$. The solution was stirred at room temperature for $5-10 \mathrm{~min}$. To this solution, solid sodium borohydride $(0.567 \mathrm{~g}, 10$ equiv. $15 \mathrm{mmol}$ ) was added in small instalments and the reaction mixture was heated at $50{ }^{\circ} \mathrm{C}$ for the required time (almost $30 \mathrm{~min}$ ) to complete the reaction as monitored by using TLC. It was cooled to room temperature and then filtered. The filtrate was extracted with ethyl acetate $(3 \times 10 \mathrm{~mL})$. The 
combined organic extract was washed with brine $(20 \mathrm{~mL})$, dried over anhydrous $\mathrm{Na}_{2} \mathrm{SO}_{4}$ and concentrated under vacuum. The crude material so obtained was purified by column chromatography.

\section{Results and Discussion}

\subsection{Characterization of resin-encapsulated nickel nanocatalyst}

\subsubsection{Field emission Scanning Electron Microscopy} (FESEM) and High-Resolution Transmission Electron Microscopy (HR-TEM): FESEM was carried out to study topography and elemental information of the surface of resin beads encapsulated with nickel nanoparticles. FESEM images depict the smooth dispersion of nickel nanoparticles into the matrix and on the surface of beads. FESEM images show no obvious contamination or agglomeration of metal nanoparticles on the surface of the resin beads (Figure 1).

The resin beads were immersed in ethanol that developed the nanopores in microporous resins. The nanopores of the microporous XAD-4 resin can control the growth of metal nanoparticles resulting in concise distribution in the size of nickel nanoparticles. Figure 2 depicts the HR-TEM images of synthesized nickel nanocatalyst. HR-TEM analysis was used to know the morphology and dimension of nickel nanoparticles embedded in the matrix of resin. Resin beads were dispersed in ethanol through sonication. The analysis was done by putting a drop of this dispersion on carbon-coated copper grids. The typical TEM images of freshly prepared nickel nanocatalyst show uniform and well-dispersed spherical nickel nanoparticles with a dimension between 5 and $8 \mathrm{~nm}$ (average size $6.7 \pm$ $3.03 \mathrm{~nm}$ ) as revealed through particle size distribution TEM-histogram (Figure 2c).
TEM-EDS analysis reveals the presence of only nickel metal and it is found to be $10.24 \mathrm{wt} \%$ in elemental composition. The inset TEM shows the SAED pattern of nickel nanocatalyst displayed with bright spots and good ring pattern that specifies the crystallinity of nickel nanoparticles.

\subsubsection{Inductively Coupled Plasma-Mass Spectroscopy} (ICP-MS): The concentration of nickel nanoparticles deposited on resin could be figured out by ICP-MS. $500 \mathrm{mg}$ of resin-encapsulated nanocatalyst was incinerated in a silica crucible for $4 \mathrm{~h}$ at $550^{\circ} \mathrm{C}$, and then the residue was dissolved in $1 \mathrm{~mL}$ of Aqua-regia and diluted up to $5 \mathrm{~mL}$ with distilled water. The average concentration of nickel metal deposited on resin was calculated as $0.00916 \mathrm{mmol} / \mathrm{g}$ or $0.538 \mathrm{mg} / \mathrm{g}$ of the resin in at least three trials.

\subsection{Optimization of the reaction conditions for the reduction of nitroarenes}

The catalytic performance of resin-encapsulated nickel nanocatalyst has been investigated in the reduction of nitroarenes. For the optimization of the reaction conditions, a series of experiments were carried out, involving the variation in reducing agent, amount of resinencapsulated nickel nanocatalyst, temperature, and solvent combinations. The reduction of 4-nitrotoluene $(0.205 \mathrm{~g}, 1.5 \mathrm{mmol})$ was chosen as the model reaction to give the 4-aminotoluene. Increasing the amount of sodium borohydride from 5 equivalents to 10 equivalents for 4-nitrotoluene, the yield of the desired product increased from 70 to $95 \%$ (Table 1, entries 2-4). Further increase in the amount of sodium borohydride did not result in any increase in the yield (Table 1, entry 12). Decreasing the amount of nickel nanocatalyst resulted in the decrease in the yield of the product. However,
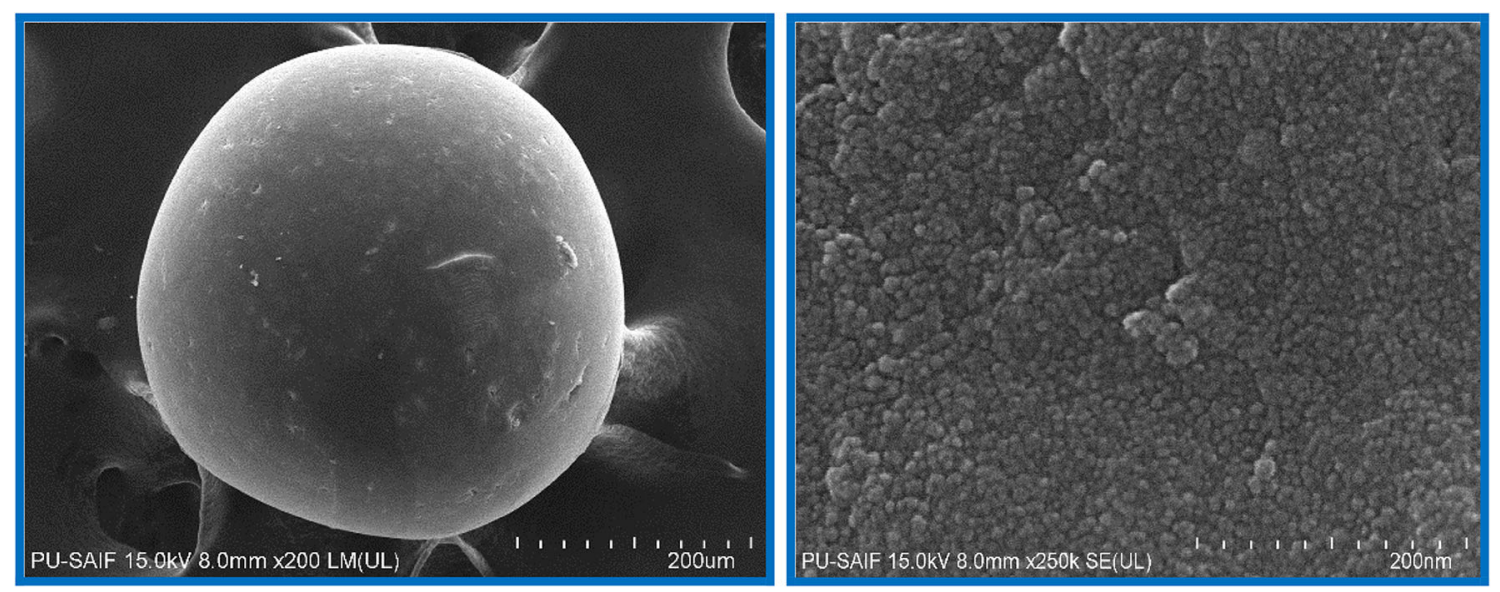

Figure 1. FESEM images of resin bead with nickel nanoparticles (1-2). 
(a)

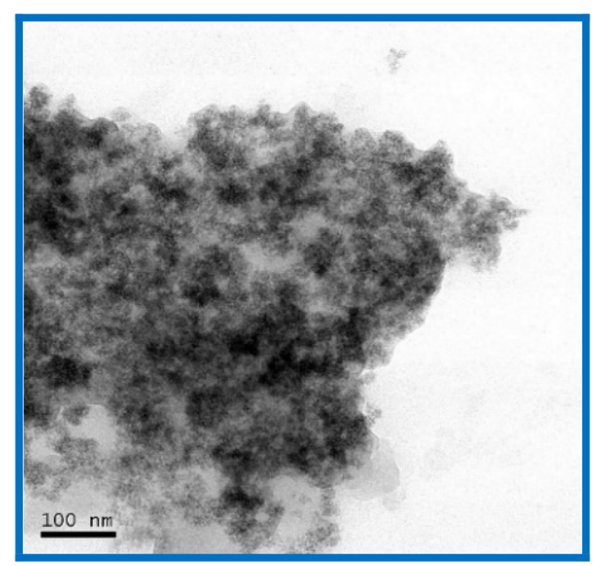

(d)

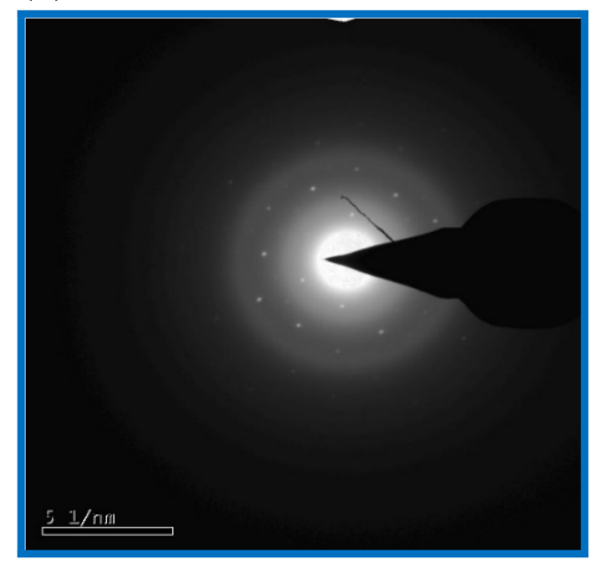

(b)

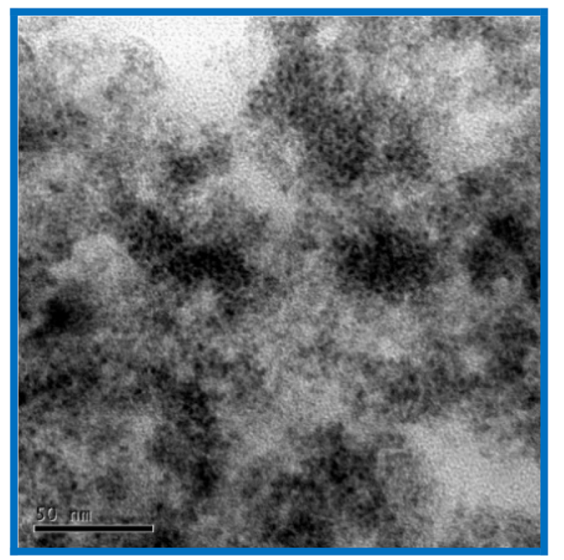

(c)

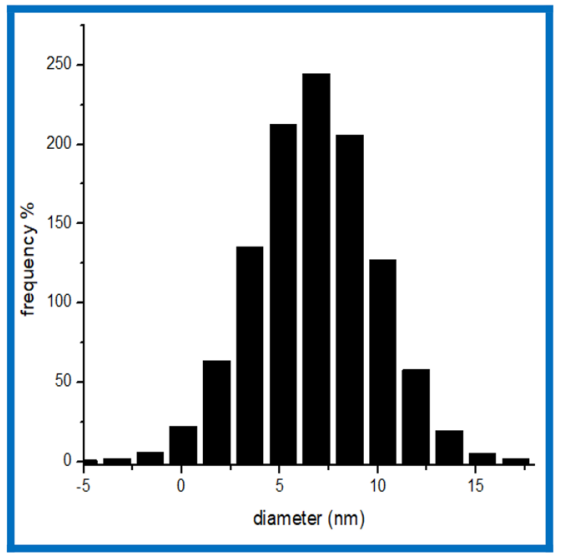

(e)

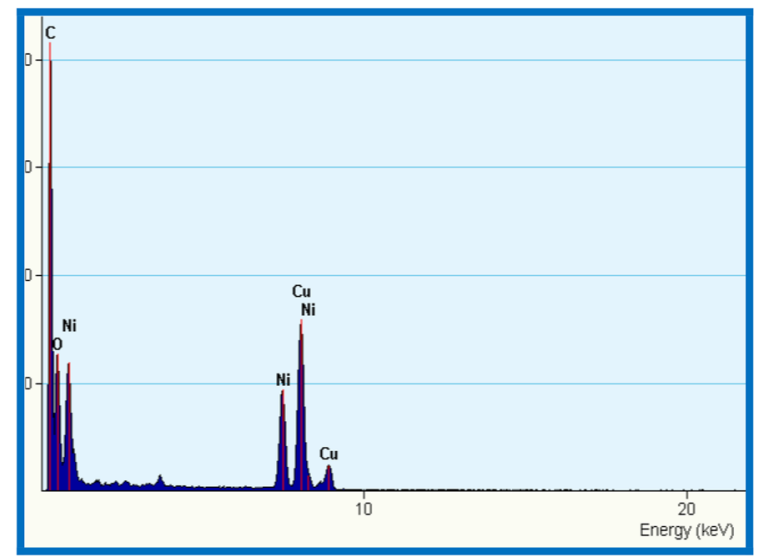

Figure 2. HR-TEM images (a-b), particle size distribution histogram (c), SAED pattern (d) and TEM-EDS images (e) of freshly prepared resin-encapsulated nickel nanocatalyst.

the yield did not improve on increasing the amount of nickel nanocatalyst (from 300 to $350 \mathrm{mg}$ ) under similar conditions (Table 1, entries 5, 8-11).

The effect of solvent on the yield and time of the reaction was also examined. Water and methanol were more efficient compared to other solvents like ethanol, DCM and THF (Table 1, entries 5, 13, and 15-19). The best yield was obtained using a combination of methanol: water $(\mathrm{v} / \mathrm{v}=3 / 7)$ at $50{ }^{\circ} \mathrm{C}$. Even when the reaction was carried out in water only, the desired product 4-aminotoluene (Table 1, entry 17) was obtained in good yield $(68 \%)$. When the reduction was carried out at room temperature, the product was obtained in a lower yield (Table 1, entry 14). However, no reaction occurred in the absence of either catalyst or reducing agent (Table 1 , entries 1,20 ). The best results were obtained using 4-nitrotoluene $(0.205 \mathrm{~g}, 1.5 \mathrm{mmol})$, $300 \mathrm{mg}$ resin-encapsulated nickel nanocatalyst with sodium borohydride $(0.567 \mathrm{~g}, 10$ equiv. $15 \mathrm{mmol})$ in $10 \mathrm{~mL}$ of $\mathrm{CH}_{3} \mathrm{OH}: \mathrm{H}_{2} \mathrm{O}(3: 7)$ at $50{ }^{\circ} \mathrm{C}$ (Table 1 , entry 5).

\subsection{General scope of the reaction}

With the optimized reaction conditions in hand, resin-encapsulated nickel nanocatalyst was further evaluated for the reduction of different functionalized nitroarenes. The synthesized resin-encapsulated nickel nanocatalyst was found to be compatible with arenes having electron-donating as well as electronwithdrawing substituents at any position (Table 2). Amino, methoxy, and methyl substituted nitroarenes were reduced to corresponding amines in good yield.

It was found that both 4-chloro and 4-bromo substituted nitroarenes were reduced to their corresponding amines without any dehalogenation taking place (Table 2, entries 8,9). The 4-chloroaniline so obtained is an important ingredient for the synthesis of antimalarial drug paludrine. The nitro group in the heterocyclic system was reduced to give the corresponding amine in good yield (Table 2, entries 11, 15). 8-Aminoquinoline (2k) is an important ingredient for the synthesis of antimalarial drugs primaquine and pamaquine. 
Table 1. Optimization of reaction conditions for reduction of 4-nitrotoluene.

\begin{tabular}{|c|c|c|c|c|c|c|c|}
\hline Entry & $\begin{array}{l}\text { Substrate } \\
\text { 1a (mmol) }\end{array}$ & $\mathrm{NaBH}_{4}$ (equiv.) & Amount of resin (mg) & Solvent & Temp. $\left({ }^{\circ} \mathrm{C}\right)$ & Time (h) & Yield $^{\mathrm{a}}(\%)$ \\
\hline 1. & 1.5 & 5 & 0 & $\mathrm{CH}_{3} \mathrm{OH}: \mathrm{H}_{2} \mathrm{O}(3: 7)$ & 50 & 1 & 0 \\
\hline 2. & 1.5 & 5 & 300 & $\mathrm{CH}_{3} \mathrm{OH}: \mathrm{H}_{2} \mathrm{O}(3: 7)$ & 50 & 2 & 70 \\
\hline 3. & 1.5 & 7 & 300 & $\mathrm{CH}_{3} \mathrm{OH}: \mathrm{H}_{2} \mathrm{O}(3: 7)$ & 50 & 2 & 85 \\
\hline 4. & 1.5 & 10 & 300 & $\mathrm{CH}_{3} \mathrm{OH}: \mathrm{H}_{2} \mathrm{O}(3: 7)$ & 50 & 1 & 95 \\
\hline 5. & 1.5 & 10 & 300 & $\mathrm{CH}_{3} \mathrm{OH}: \mathrm{H}_{2} \mathrm{O}(3: 7)$ & 50 & 0.5 & 95 \\
\hline 6. & 1.5 & 10 & 300 & $\mathrm{CH}_{3} \mathrm{OH}: \mathrm{H}_{2} \mathrm{O}(3: 7)$ & 50 & 0.35 & 90 \\
\hline 7. & 1.5 & 10 & 300 & $\mathrm{CH}_{3} \mathrm{OH}: \mathrm{H}_{2} \mathrm{O}(3: 7)$ & 50 & 1 & 95 \\
\hline 8. & 1.5 & 10 & 350 & $\mathrm{CH}_{3} \mathrm{OH}: \mathrm{H}_{2} \mathrm{O}(3: 7)$ & 50 & 1 & 95 \\
\hline 9. & 1.5 & 10 & 250 & $\mathrm{CH}_{3} \mathrm{OH}: \mathrm{H}_{2} \mathrm{O}(3: 7)$ & 50 & 1 & 80 \\
\hline 10. & 1.5 & 10 & 200 & $\mathrm{CH}_{3} \mathrm{OH}: \mathrm{H}_{2} \mathrm{O}(3: 7)$ & 50 & 1 & 70 \\
\hline 11. & 1.5 & 10 & 100 & $\mathrm{CH}_{3} \mathrm{OH}: \mathrm{H}_{2} \mathrm{O}(3: 7)$ & 50 & 1 & 50 \\
\hline 12. & 1.5 & 12 & 300 & $\mathrm{CH}_{3} \mathrm{OH}: \mathrm{H}_{2} \mathrm{O}(3: 7)$ & 50 & 0.5 & 95 \\
\hline 13. & 1.5 & 10 & 300 & $\mathrm{CH}_{3} \mathrm{OH}: \mathrm{H}_{2} \mathrm{O}(1: 1)$ & 50 & 1 & 85 \\
\hline 14. & 1.5 & 10 & 300 & $\mathrm{CH}_{3} \mathrm{OH}: \mathrm{H}_{2} \mathrm{O}(3: 7)$ & 25 & 2 & 60 \\
\hline 15. & 1.5 & 10 & 300 & $\mathrm{CH}_{3} \mathrm{OH}$ & 50 & 1 & 65 \\
\hline 16. & 1.5 & 10 & 300 & $\mathrm{EtOH}$ & 50 & 1 & 50 \\
\hline 17. & 1.5 & 10 & 300 & $\mathrm{H}_{2} \mathrm{O}$ & 50 & 1 & 68 \\
\hline 18. & 1.5 & 10 & 300 & DCM & 50 & 1 & 30 \\
\hline 19. & 1.5 & 10 & 300 & THF & 50 & 1 & Trace \\
\hline 20. & 1.5 & - & 300 & $\mathrm{CH}_{3} \mathrm{OH}: \mathrm{H}_{2} \mathrm{O}(3: 7)$ & 50 & 1 & 0 \\
\hline
\end{tabular}

${ }^{a}$ Isolated yield.

Table 2. Reduction of nitroarenes using resin-encapsulated nickel nanocatalyst and $\mathrm{NaBH}_{4}$ as mild reducing agent ${ }^{\mathrm{a}}$.

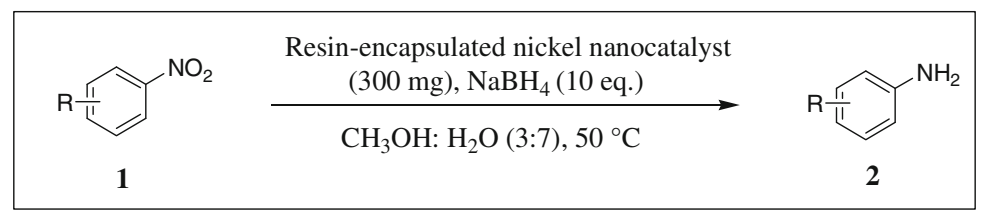

\begin{tabular}{|c|c|c|c|c|}
\hline Entry no. & Reactant $\mathbf{1}$ & Product 2 & Time (h) & Yield $^{\mathrm{b}}(\%)$ \\
\hline 1. & 4-Nitrotoluene (1a) & 4-Aminotoluene (2a) & 0.5 & 95 \\
\hline 2. & 3-Nitrotoluene (1b) & 3-Aminotoluene (2b) & 2 & 82 \\
\hline 3. & Nitrobenzene (1c) & Aniline (2c) & 1 & 90 \\
\hline 4. & 4-Nitrophenol (1d) & 4-Aminophenol (2d) & 0.5 & 80 \\
\hline 5. & 4-Methoxynitrobenzene (1e) & 4-Methoxyaniline (2e) & 1 & 90 \\
\hline 6. & 3-Methoxynitrobenzne (1f) & 3-Methoxyaniline (2f) & 2 & 86 \\
\hline 7. & 4-Nitrobenzaldehyde (1g) & 4-Aminobenzylalcohol (2g) & 2 & 82 \\
\hline 8. & 4-Chloronitrobenzene (1h) & 4-Aminochlorobenzene (2h) & 2 & 88 \\
\hline 9. & 4-Bromonitrobenzene (1i) & 4-Aminobromobenzene (2i) & 2 & 80 \\
\hline 10. & 1-Nitronaphthalene (1j) & 1-Aminonaphthalene $(\mathbf{2} \mathbf{j})$ & 2 & 90 \\
\hline 11. & 8-Nitroquinoline (1k) & 8-Aminoquinoline (2k) & 2 & 80 \\
\hline 12. & 4-Aminonitrobenzene (11) & 1,4-Diaminobenzene (2l) & 1 & 93 \\
\hline 13. & 3-Aminonitrobenzene (1m) & 1,3-Diaminobenzene (2m) & 2 & 79 \\
\hline 14. & 2-Aminonitrobenzene (1n) & 1,2-Diaminobenzene (2n) & 2 & 92 \\
\hline 15. & 2-Nitropyridine (10) & 2-Aminopyridine (2o) & 2 & 80 \\
\hline
\end{tabular}

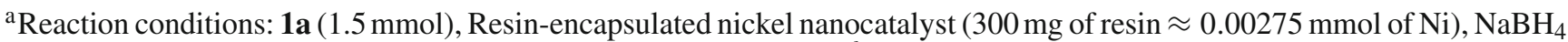
$(0.567 \mathrm{~g}, 10$ equiv., $15 \mathrm{mmol})$ at $0{ }^{\circ} \mathrm{C}, \mathrm{CH}_{3} \mathrm{OH}: \mathrm{H}_{2} \mathrm{O}(3: 7), 50^{\circ} \mathrm{C}$. ${ }^{b}$ isolated yield after column chromatography.

\subsection{UV-Vis study of the reduction reaction}

The reduction of nitroarenes can be effectively catalyzed by metal nanocatalyst only when the potential of metal nanocatalyst is located in between the potential of $\mathrm{BH}_{4}^{-}$and nitroarenes. Bordbar et al. ${ }^{40}$ have described the reduction of 4-nitrophenol (4-NP) to 4-aminophenol (4-AP) using borohydride ion in the 
presence of immobilized nickel nanoparticles on polymer/mesoporous composite. Also, Song and coworkers ${ }^{41}$ reported the catalytic activity of $\mathrm{Ru}$ nanoparticles as an efficient catalyst for the reduction of 4-nitrophenol to 4-aminophenol using $\mathrm{NaBH}_{4}$. We have also studied the catalytic activity of synthesized resin-encapsulated nickel nanocatalyst by the selective reduction of 4-nitrophenol to 4-aminophenol using $\mathrm{NaBH}_{4}$ as a mild reducing agent. This reaction is easy to follow using UV-Visible spectroscopy. ${ }^{42}$ The reaction was started by dissolving 4-nitrophenol $(0.208 \mathrm{~g}, 1.5 \mathrm{mmol})$ in $10 \mathrm{~mL}$ of $\mathrm{CH}_{3} \mathrm{OH}: \mathrm{H}_{2} \mathrm{O}(3: 7)$, followed by addition of nickel nanocatalyst $(300 \mathrm{mg})$ and $\mathrm{NaBH}_{4}(0.567 \mathrm{~g}, 10$ equiv. $15 \mathrm{mmol})$. The reaction mixture was heated to $50{ }^{\circ} \mathrm{C}$ and then subjected to UV-Visible study by taking $0.3 \mathrm{~mL}$ aliquot, from the reaction mixture at regular intervals and diluting it to $5 \mathrm{~mL}$ with $10 \% \mathrm{HCl}$. Dilute $\mathrm{HCl}$ was used to decompose the excess amount of $\mathrm{NaBH}_{4}$ present in the sample aliquot. The UV-Visible absorption spectrum of the aqueous solution of 4-nitrophenol and the resin-encapsulated nickel nanocatalyst showed an absorption peak at $317 \mathrm{~nm}$. On the addition of $\mathrm{NaBH}_{4}$ into the 4-nitrophenol solution, the absorption peak shifted to $400 \mathrm{~nm}$, with a change in the color from original light yellow to intense yellow (Figure S4 (A-E), Supplementary Information). This is due to the transformation of 4-nitrophenol to the 4-nitrophenolate anion. The progress of the catalytic reduction of the 4-nitrophenol to 4-aminophenol was monitored by the change in the intensity of the absorbance peak at $317 \mathrm{~nm}$ in the UV-Visible spectrum. The time-dependent UVVisible absorption spectra of 4-nitrophenol and $\mathrm{NaBH}_{4}$ solution in the presence of as-prepared nickel nanocatalyst is shown in Figure S5, Supplementary Information. It has been observed that with the progress of the reaction, the intensity of the absorption peak of 4nitrophenol at $317 \mathrm{~nm}$ decreased gradually and finally disappeared and a new peak at $295 \mathrm{~nm}$ appeared, signifying that 4-nitrophenol gradually converted to the (a)

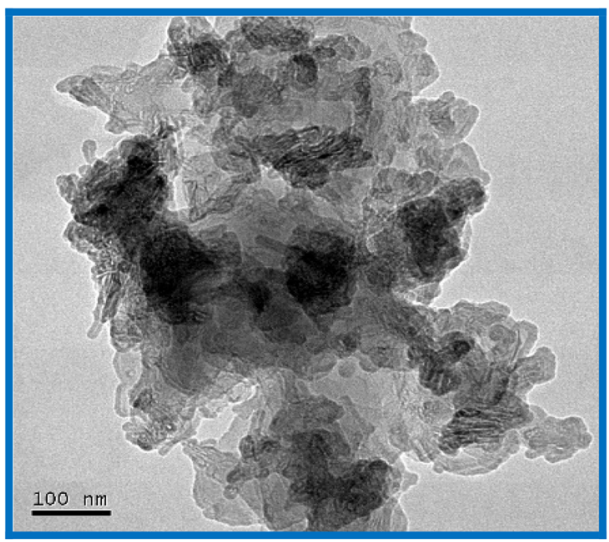

(b)

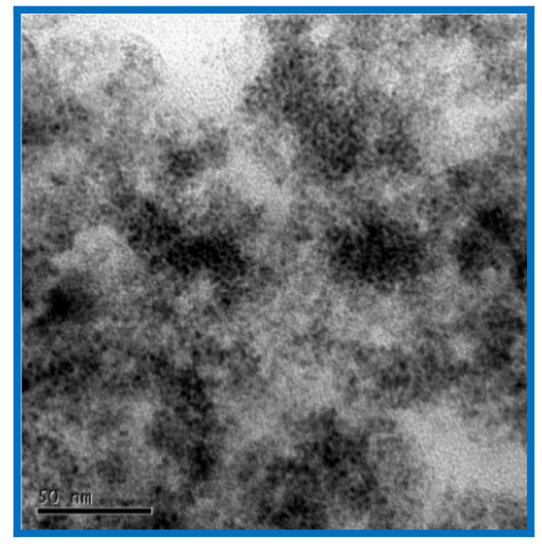

(c)

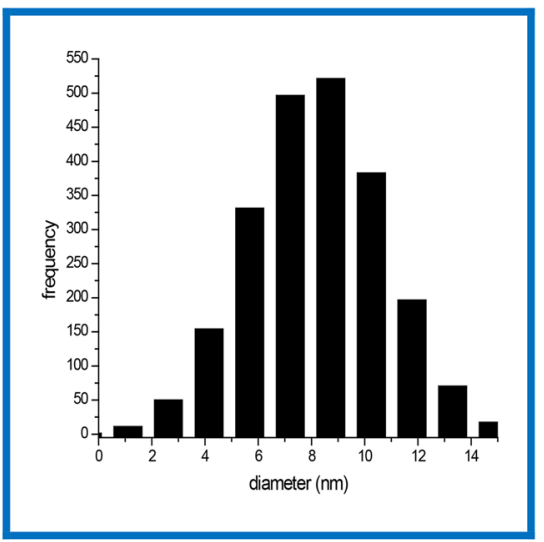

(d)

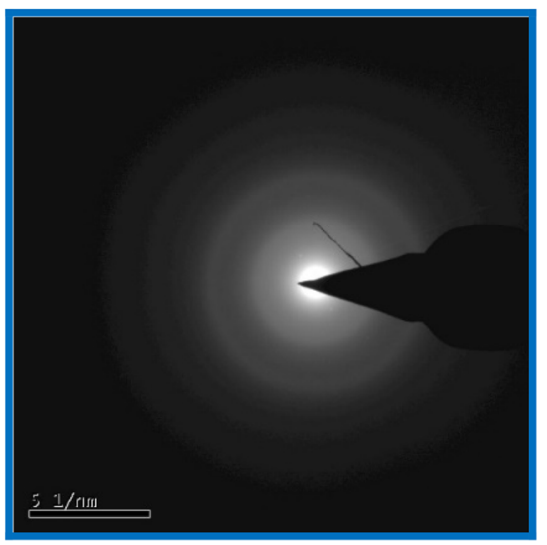

(e)

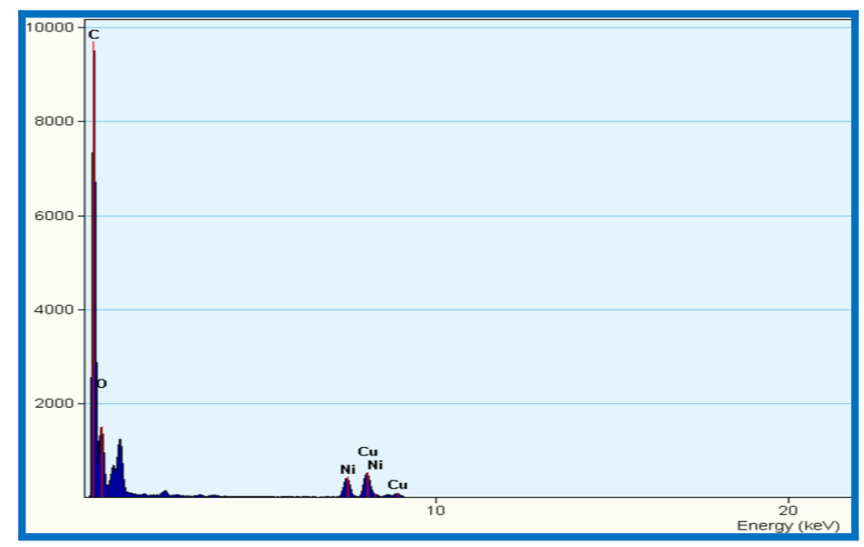

Figure 3. HR-TEM images, particle size distribution histogram, SAED pattern and TEM-EDS images (a-e) of resin-encapsulated nickel nanocatalyst after fifth recycle for reduction of 4-nitrotoluene. 
Table 3. Comparison of catalytic activity of present nanocatalyst with the earlier reported results

\begin{tabular}{|c|c|c|c|c|c|}
\hline Entry no. & Nanocatalyst & Time & Conditions & Reusability & Reference \\
\hline 1. & Ni@organic modifier & $8 \mathrm{~h}$ & $\begin{array}{l}\text { 0.8 MPa pressure, } \\
100^{\circ} \mathrm{C} \text {, anhydrous } \\
\text { ethanol }\end{array}$ & Up to four cycles & 43 \\
\hline 2. & Ni@p(4-VP) cryogels & $60 \mathrm{~min}$ & $\begin{array}{l}\text { Nitro compound } \\
(0.01 \mathrm{M}), \mathrm{NaBH}_{4} \\
(0.4 \mathrm{M}), 30^{\circ} \mathrm{C} \\
800 \mathrm{rpm}\end{array}$ & Up to four cycles & 44 \\
\hline 3. & Ni@ carbon filaments & $12-24 \mathrm{~h}$ & $1.5 \mathrm{MPa}$ of $\mathrm{H}_{2}, 120^{\circ} \mathrm{C}$ & Single time & 45 \\
\hline 4. & $\begin{array}{l}\text { Nanosized Nickel } \\
\text { decorated sisal fibers }\end{array}$ & $10 \min$ & $\begin{array}{c}\text { Substrate }(1.0 \mathrm{mmol}), \\
\mathrm{NaBH}_{4}(100 \mathrm{mmol}) \\
\text { catalyst }(3.39 \%)\end{array}$ & Up to seven cycles & 45 \\
\hline 5. & $\begin{array}{l}\mathrm{Ni} / \text { Carbide-Ni/carbon } \\
\text { nanofibers } \\
\text { nanocomposite }\end{array}$ & $2.5 \mathrm{~h}$ & 2.0 $\mathrm{MPa}$ of $\mathrm{H}_{2}, 140^{\circ} \mathrm{C}$ & Up to five cycles & 46 \\
\hline 6. & $\mathrm{Fe}(0) \mathrm{nps}$ & $3-4 h$ & $\begin{array}{l}\text { 80-96\%, Substrate } \\
\quad(1.0 \mathrm{mmol}), \text { catalyst } \\
\text { (3 equiv.) }\end{array}$ & Single time & 38 \\
\hline 7. & Ni@XAD-4 nanocatalyst & $20-80 \mathrm{~min}$ & $\begin{array}{l}95-80 \%, 0.00275 \mathrm{mmol} \\
\text { nanocatalyst for } \\
1.5 \mathrm{mmol}^{\text {of substrate, }} \\
\mathrm{NaBH}_{4} \text { (10 equiv.) }\end{array}$ & Up to five cycles & $\begin{array}{l}\text { Present } \\
\text { work }\end{array}$ \\
\hline
\end{tabular}

corresponding 4-aminophenol. This was accompanied by the change in color from yellow to colorless.

\subsection{Recyclability of resin-encapsulated nickel nanocatalyst}

The recyclability and reusability of resin-encapsulated nickel nanocatalyst was demonstrated in the reduction of 4-nitrotoluene. The reaction was carried out with 4-nitrotoluene $(0.205 \mathrm{~g}, 1.5 \mathrm{mmol})$ and nickelencapsulated nickel nanocatalyst $(300 \mathrm{mg})$ in $10 \mathrm{~mL}$ of $\mathrm{CH}_{3} \mathrm{OH}: \mathrm{H}_{2} \mathrm{O}(3: 7)$ at $0^{\circ} \mathrm{C}$ and followed by the addition of $\mathrm{NaBH}_{4}(0.567 \mathrm{~g}, 10$ equiv. $)$ in small instalments. The reaction mixture was heated to $50{ }^{\circ} \mathrm{C}$ and stirred at the same temperature for $30 \mathrm{~min}$. After completion of the reaction, as monitored by TLC nickel nanocatalyst was recovered by filtration, and washed with distilled water, followed by ethanol and reused as such in the next reaction. The nanocatalyst was successfully recycled and reused up to five cycles without a significant decrease in its catalytic efficiency $(95 \%, 95 \%, 94 \%, 90 \%$ and 90\%) as shown in Figure S6 (Supplementary Information). The characterization of used nickel nanocatalyst through HR-TEM analysis shows that the morphology and size of nickel nanocatalyst remains almost the same (spherical and average size $8.1 \pm 2.55 \mathrm{~nm}$ ) after use for the fifth cycle. Slight variation in the concentration of nickel impregnation is there as revealed by the HR-TEM images and TEM-EDS analysis (Figure 3).

\subsection{Comparison of catalytic activity of present} nanocatalyst with the earlier reported nickel and other nanocatalysts towards reduction of nitroarenes

This section features Table 3 .

\section{Conclusions}

In conclusion, an inexpensive and recyclable resin-encapsulated nickel nanocatalyst has been synthesized using a modified impregnation method and characterized by using FESEM, HR-TEM, TEM-EDS, and ICP-MS techniques. This protocol offers advantages such as easy accessibility, easy product isolation, ecofriendly, and recyclability of the nanocatalyst for the reduction of nitroarenes.

\section{Supplementary Information (SI)}

The synthesized resin-encapsulated nickel nanocatalyst is characterized by FESEM, HR-TEM, TEM-EDS, and ICP-MS techniques. FESEM and HR-TEM, particle size distribution histogram, and TEM-EDS images of the synthesized resinencapsulated nickel nanocatalyst are given in SI (Figures S1, S2 and S3). The ${ }^{1} \mathrm{H}$ NMR and ${ }^{13} \mathrm{C}$ NMR spectral data and spectra of aromatic amines obtained on the reduction of nitroarenes with resin-encapsulated nickel nanocatalyst are given in Appendix A of Supplementary Information, available at www.ias.ac.in/chemsci. 


\section{Acknowledgements}

The authors acknowledge the financial support from Science and Engineering Research Board (SERB)-DST, New Delhi, through Scheme number EEQ/2016/000574, CRF, IIT Delhi for HR-TEM and TEM-EDS analysis, PBTI, Mohali for ICP-MS characterization and SAIF, Punjab University for ${ }^{1} \mathrm{H}$ NMR and ${ }^{13} \mathrm{C}$ NMR and other characteristic techniques.

\section{References}

1. Talmage S S, Opresko D M, Maxwell C J, Welsh C J, Cretella F M, Reno P H and Daniel F B 1999 Nitroaromatic munition compounds: environmental effects and screening values Rev. Environ. Contam. Toxicol. 1611

2. Kovacic P and Somanathan R 2014 Nitroaromatic compounds: Environmental toxicity, carcinogenicity, mutagenicity, therapy and mechanism J. Appl. Toxicol. 34 810

3. Yan F, He Y, Ding L and Su B 2015 Highly ordered binary assembly of silica mesochannels and surfactant micelles for extraction and electrochemical analysis of trace nitroaromatic explosives and pesticides Anal. Chem. 874436

4. Liu X, Ma X, Liu S, Liu Y and Xia C 2015 Metal fluoride promoted catalytic hydrogenation of aromatic nitro compounds over RANEY® Ni RSC Adv. 536423

5. Deiber G, Foussard J N and Debellefontaine H 1997 Removal of nitrogenous compounds by catalytic wet air oxidation. Kinetic study Environ. Pollut. 96311

6. Keiichi T, Wandee L and Teruaki H 1997 Photocatalytic degradation of mono-, di- and trinitrophenol in aqueous $\mathrm{TiO}_{2}$ suspension. J. Mol. Catal. A: Chem. 12267

7. Clemenceau A, Wang Q and Zhu J 2018 Cooperative $\mathrm{Pd} / \mathrm{Cu}$ catalysis: multicomponent synthesis of tetrasubstituted imidazolones from methyl $\alpha$ Isocyanoacetates, primary amines, and aryl(vinyl) iodides Org. Lett. 20 126

8. Mei N, Liu B and Bing V Int. 2016 Pd nanoparticles supported on Fe3O4@C: An effective heterogeneous catalyst for the transfer hydrogenation of nitro compounds into amines J. Hydrog. Energy 4117960

9. Morse J R, Callejas J F, Darling A J and Schaak R E 2017 Bulk iron pyrite as a catalyst for the selective hydrogenation of nitroarenes Chem. Commun. $\mathbf{5 3} 4807$

10. Kalyanaraman V and George M V 1973 Alkali metal reduction of aromatic nitro compounds J. Org. Chem. $\mathbf{3 8}$ 507

11. Asghar A S and Kazemi F 2016 Photocatalytic reduction of nitroaromatic compounds to amines using a nanosized highly active $\mathrm{CdS}$ photocatalyst under sunlight and blue LED irradiation Chem. Pap. 70531

12. Qi Z, Dong H, Yu H, Zhao M and Yu H 2017 In-situ electrochemical NOx removal process for the lean-burn engine exhaust based on carbon black gas diffusion electrode J. Clean. Prod. 151465

13. Li Y, Gong Y, Xu X, Zhang P, Li H and Wang Y 2012 A practical and benign synthesis of amines through $\mathrm{Pd} @ \mathrm{mpg}-\mathrm{C}_{3} \mathrm{~N}_{4}$ catalyzed reduction of nitriles Catal. Commun. 289
14. Blanita G and Lazar M D 2013 Review of graphenesupported metal nanoparticles as new and efficient heterogeneous catalysts Micro Nanosyst. 5138

15. Segobia D, Trasarti A and Apesteguia C 2012 Hydrogenation of nitriles to primary amines on metalsupported catalysts: Highly selective conversion of butyronitrile to $n$-butylamine Appl. Catal. A $\mathbf{4 4 5}$ 69

16. Tumma M and Srivastava R 2013 Transition metal nanoparticles supported on mesoporous polyaniline catalyzed the reduction of nitroaromatics Catal. Commun. 3764

17. Jamal S, Rezaei $\mathrm{T}$, Khorramabadi H, Hesami A, Ramazani A, Amani V and Ahmadi R 2017 Chemoselective reduction of nitro and nitrile compounds with magnetic carbon nanotubes supported Pt(II) catalyst under mild conditions Ind. Eng. Chem. Res. 56 12256

18. Zuoa P, Duana J, Fana H, Qua S and Shen W 2018 Facile synthesis high nitrogen-doped porous carbon nanosheet from pomelo peel and as catalyst support for nitrobenzene hydrogenation Appl. Surf. Sci. 4351020

19. Cao Y, He L and Ni J 2011 Method for the synthesis of amine by reduction of nitro compound in presence of a metal oxide-supported gold catalyst Faming Zhuanli Shenqing CN 102086143 A 20110608

20. Mohammadi-Aghdam B, Bahari S and Molaei R 2013 The Pd (0) nanoparticles stabilized by collagen fibres as a recyclable heterogeneous catalyst for the Stille reaction under aerobic condition J. Chem. Sci. 125813

21. Hemantha H P and Sureshbabu V V 2011 Poly(vinyl)chloride supported palladium nanoparticles: a catalyst for rapid hydrogenation reactions Org. Biomol. Chem. 92597

22. Lara P and Philippot K 2014 The hydrogenation of nitroarenes mediated by platinum nanoparticles: an overview Catal. Sci. Technol. 42445

23. Chaiseeda K, Nishimura S and Ebitani K 2017 Gold nanoparticles supported on alumina as a catalyst for surface plasmon-enhanced selective reductions of nitrobenzene ACS Omega 27066

24. Feng W, Huang T, Gao L, Yang X, Deng W, Zhou R and Liu H 2018 Textile-supported silver nanoparticles as a highly efficient and recyclable heterogeneous catalyst for nitroaromatic reduction at room temperature $R S C A d v . \mathbf{8}$ 6288

25. Viswanathan P and Ramaraj R 2018 Gold nanodots selfassembled polyelectrolyte film as reusable catalyst for reduction of nitroaromatics J. Chem. Sci. 13010

26. Shang H, Pan K, Zhang L, Zhang B and Xiang X 2016 Enhanced activity of supported Ni catalysts promoted by $\mathrm{Pt}$ for rapid reduction of aromatic nitro compounds Nanometre 6103

27. Ai Y, Liua L, Jing K, Qi L, Fana Z, Zhoua J, Suna H-Bin, Shao Z and Liang Q 2017 Noncovalently functionalized carbon nanotubes immobilized Fe-Bi bimetallic oxides as a heterogeneous nanocatalyst for reduction of nitroaromatics NANOSO 10116

28. Barot N, Shaikh T and Kaur H 2017 A PLA-TiO 2 particle brush as a novel support for CuNPs: a catalyst for the fastsequential reduction and $\mathrm{N}$-arylation of nitroarenes $\mathrm{New}$ J. Chem. 415347 
29. Sorribes I, Liu L and Corma A 2017 Nanolayered CoMo-S catalysts for the chemoselective hydrogenation of nitroarenes ACS Catal. 72698

30. Ayoub H, Lair V, Griveau S, Brunswick P, Bedioui F and Cassir M 2011 SUDOSCAN device for the early detection of diabetes: in vitro measurement versus results of clinical tests Sensor Lett. 92147

31. Yu J and Xu G 2018 A kind of cobalt nickel super capacitor electrode and its preparation process [Machine Translation] Faming Zhuanli Shenqing CN 107658150 A 20180202

32. Jamal S, Rezaei $\mathrm{T}$, Malekzadeh A M, Poulaei S, Ramazani A and Khorramabadi H 2018 Chemoselective reduction of nitro and nitrile compounds using Ni nanoparticles immobilized on hyperbranched polymer-functionalized magnetic nanoparticles Appl. Organometal. Chem. 323975

33. Meng X, Cheng H, Akiyama Y, Hao Y, Qiao W, Yu Y, Zhao F, Fujita S and Arai M 2009 Selective hydrogenation of nitrobenzene to aniline in dense phase carbon dioxide over $\mathrm{Ni} / \mathrm{C}-\mathrm{Al}_{2} \mathrm{O}_{3}$ : significance of molecular interactions $J$. Catal. 2641

34. Romanazzi G, Fiore A M, Malia M, Rizzuti A, Leonelli C, Nacci A, Mastrorilli P and Dell'Annaa M M 2018. Polymer supported Nickel nanoparticles as recyclable catalyst for the reduction of nitroarenes to anilines in aqueous medium Mol. Catal. 44631

35. Yadagiri J, Koppadi K S, Enumula S S, Vakati V, Kamaraju S R R, Burri D R and Somaiah P V 2018 Ni/KIT-6 catalysts for hydrogenolysis of lignin-derived diphenyl ether J. Chem. Sci. 130106

36. Kalbasi R J, Nourbakhsh A A and Babaknezhad F 2011 Synthesis and characterization of Ni nanoparticlespolyvinylamine/SBA-15 catalyst for simple reduction of aromatic nitro compounds Catal. Commun. 12955

37. Mahata N, Cunha A F, Orfao J J M and Figueiredo J L 2008 Hydrogenation of nitrobenzene over nickel nanoparticles stabilized by filamentous carbon Appl. Catal. A: Gen. 351204
38. Dey R, Mukherjee N, Ahammed S and Ranu B C 2012 Highly selective reduction of nitroarenes by iron(0) nanoparticles in water Chem. Commun. 487982

39. Shah D and Kaur H 2014 Resin-trapped gold nanoparticles: An efficient catalyst for reduction of nitro compounds and Suzuki-Miyaura coupling J. Mol. Catal. A: Chem. 38170

40. Bordbar M 2017 Biosynthesis of Ag/almond shell nanocomposite as a cost-effiective and efficient catalyst for degradation of 4-nitrophenol and organic dyes $R S C$ Adv. 7180

41. Zhao Y, Luo Y, Yang X, Yang Y and Song Q 2017 Tunable preparation of ruthenium nanoparticles with superior size-dependent catalytic hydrogenation properties J. Hazard. Mater. 332124

42. Kang H, Kim M and Park K H 2015 Effective immobilization of gold nanoparticles on core-shell thiolfunctionalized $\mathrm{GO}$ coated $\mathrm{TiO}_{2}$ and their catalytic application in the reduction of 4-nitrophenol Appl. Catal. A. Gen. 502239

43. Wang A, Yin H, Lu H, Xue J, Ren M and Jiang T 2009 Effect of organic modifiers on the structure of nickel nanoparticles and catalytic activity in the hydrogenation of $p$-nitrophenol to $p$-aminophenol Langmuir $\mathbf{2 5}$ 12736

44. Sahiner N, Yildiz S and Al-Lohedan H 2015 The resourcefulness of $p(4-\mathrm{VP})$ cryogels as template for in situ nanoparticle preparation of various metals and their use in $\mathrm{H}_{2}$ production, nitro compound reduction and dye degradation Appl. Catal. B: Environ. 166145

45. Liu K, Wang Y, Cheng P, Liu Y, Kong C, Yi Z, Li M, Liu Q, Zhong W, Takagi H and Wang D 2018 Nanosized nickel decorated sisal fibers with tailored aggregation structures for catalysis reduction of toxic aromatic compounds Ind. Crops Prod. 119226

46. Kang J, Han R, Wang J, Yang L, Fan G and Li F 2015 In situ synthesis of nickel carbide-promoted nickel/carbon nanofibers nanocomposite catalysts for catalytic applications Chem. Eng. J. 27536 